\section{Use of PowerLab in Handgrip Force Measurement}

PowerLab is considered the world's first data acquisition system designed for the field of life sciences research, which provides faster results with computed analysis. 1 This advanced digital data recording technology comprised of hardware and many softwares, with improved applications and efficiency in terms of various human parameters, including muscle activity. ${ }^{2}$ The software for muscle physiology is named LabTutor, with which we can quantify and analyse handgrip force directly in percentages, which was previously measured in kilograms, pounds, milliliters of mercury and even in Newtons. ${ }^{1}$ Handgrip force is devoted to unit forces with zero ultimate value applied by hand digits on any object with contact interface. Maximum grip force is obtained by forceful flexion of all fingers with maximum voluntary power under physiological bio-kinetic environment. ${ }^{3}$ Literature showed disparity in terms of association between handgrip force and BMI (body mass index), as many studies from different ethnicities, ages, genders, work nature and eating habits, announced a positive link between the handgrip force and BMI in both genders and in all age groups, while others explored no relationship between the two variables. ${ }^{4}$

It has already been an established fact that males have more grip force compared to females in all ages. ${ }^{5}$ Here, we aim to exhibit this gender-based difference in percentages, which is a quite unique concept as according to our best knowledge no one yet has attempted to do it in this manner. We directly measured the values related to handgrip force with the use of PoweLab, because this digital device itself showed values of grip force in percentages when connected to its grip force transducer. Thus, we assessed the genderbased difference of maximum and mean handgrip force, directly in percentages through PowerLab, in young adults and also observed the role of BMI in connection to handgrip force.

Thirty participants were taken in this study through convenience sampling, consisting of 15 boys and 15 girls, ranging in-between $20-23$ years. All were the second year MBBS students of Shalamar Medical and Dental College, physically healthy and neither on any medication nor involved in any physical training programme. All participants were with right hand dominance. After explaining the procedure, a written consent was taken from each participant, and the study was approved by the Ethical Review Board of the Institution. To record weight and height of each subject,

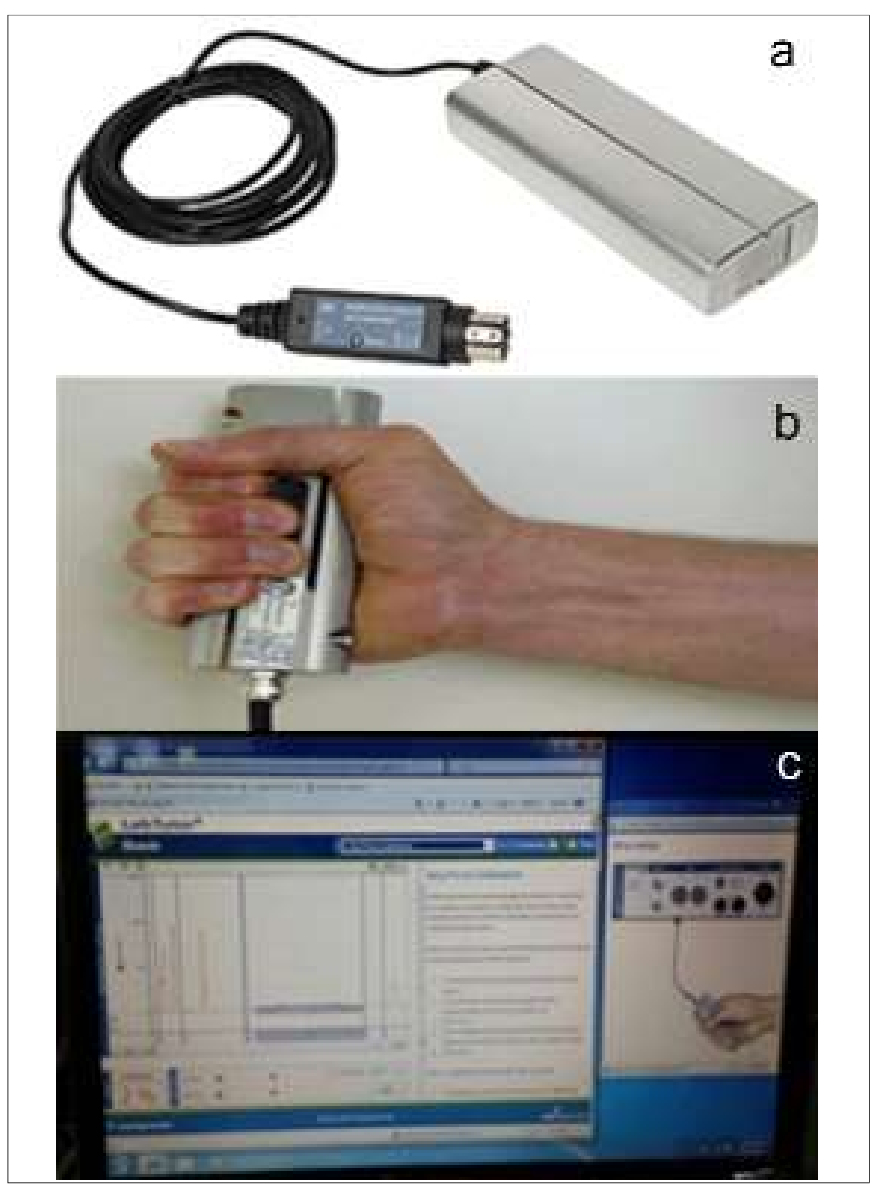

Figure 1: (a) MLT004/ST Grip Force Transducer. (b) Volunteer squeezing the "Grip Force Transducer" for maximum grip force value. (c) Digital graph showing mean grip force value on calibration window.

Adult Weighing Scale ZT-160 was used. PowerLab 2005-2007, Model 26T, made by AD Instruments with its Software "LabTutor" was used as application tool for recording and calibration of sample record. Muscle exercise "Grip Force Calibration" was further followed and the wire of "MLT004/ST Grip Force Transducer" showed in Figure 1a, was plugged to input 1 of the main hardware of PowerLab. Volunteer was asked to hold the transducer in his/her right fist as given in Figure 1b. Grip strength was shown in percentage (\%) on y-axis and time in seconds on x-axis, in the digital graph on the window, when volunteer was asked to squeeze the dynamometer as hard as possible, unless and until he/she was fatigued. Labelling on the digital graph was also done (Figure 1c). Moreover, on each axis the scale was also adjusted.

We found $>350 \%$ high value of maximum grip force in boys as compared to girls. Mean handgrip force was $48 \%$, raised in boys than girls. A $70 \%$ increased handgrip force was found in boys just before fatigue. A direct relation existed between BMI and handgrip force in boys. While in girls, there was an increase in the mean 
grip force, but a decrease in maximum handgrip force and handgrip force just before fatigue with increased BMI. Thus, boys got higher handgrip force than girls, in terms of maximum, average, and just before onset of fatigue values. The BMI showed a direct relation with hand grip force in boys. Although in girls, it was in inverse relation with handgrip force and grip force just before fatigue; but in direct relation with mean grip force $p<0.0001$.

Thus through PowerLab utilisation in biomedical sciences including physiology, pharmacology, sports and exercise, it become easier to record, calibrate and analyse the data obtained through physiological signals from human subjects.

\section{REFERENCES}

1. Aziz N, Simonetta G, Forrester K. Recent developments in data recording systems for physiology. Pak J Physiol 2006; 2:34-7.

2. Casotti G, Rieser-Danner L, Knabb MT. Successful implementation of inquiry-based physiology laboratories in undergraduate major and nonmajor courses. Adv Physiol Educ 2008; 32:286-96.
3. Incel NA, Ceceli E, Durukan PB, Erdem HR, Yorgancioglu ZR. Grip strength: Effect of hand dominance. Singapore Med $J$ 2002; 43:234-7.

4. Massy-Westropp N, Rankin W, Ahern M, Krishnan J, Hearn TC. Measuring grip strength in normal adults: Reference ranges and a comparison of electronic and hydraulic instruments. $J$ Hand Surg Am 2004; 29:514-9.

5. Lam NW, Goh HT, Kamaruzzaman SB, Chin AV, Poi PJ, Tan MP. Normative data for hand grip strength and key pinch strength, stratified by age and gender for a multiethnic Asian population. Singapore Med J 2016; 57:578-84.

Ayesha Sadiqa, Farida Munawar, Rida Muzaffar, Maham Abid, Zunaira Asghar and Nayab Fatima

Department of Physiology, Shalamar Medical and Dental College, Lahore, Pakistan

Correspondence: Prof. Farida Munawar, Head of Physiology Department, Shalamar Medical and Dental College, Lahore, Pakistan

E-mail: faridamunawar2004@yahoo.com

Received: June 20, 2018; Accepted: November 08, 2018 